\title{
Uma agenda unindo passado e futuro: os debates e realizações patrimoniais da década de 1980 e seus reflexos nas décadas seguintes em Minas Gerais
}

An agenda linking past and future: the debates and heritage achievements at the 1980's years and their reflections on the following decades at Minas Gerais, Brasil

https://doi.org/10.1590/1982-02672020v28d2e45

\section{FLÁVIO DE LEMOS CARSALADE ${ }^{1}$}

https://orcid.org/0000-0002-0729-4270

Universidade Federal de Minas Gerais / Belo Horizonte, MG, Brasil

RESUMO: Movimentos populares e institucionais redimensionaram as políticas públicas de preservação do Patrimônio na década de 1980 no estado de Minas Gerais com importantes reflexos para as décadas seguintes. No presente artigo, esses movimentos são apresentados de maneira ampla contemplando suas reivindicações e os avanços de contribuições da academia e de quadros técnicos a eles. O objetivo é mostrar como eles influenciaram as reestruturações institucionais no nível estadual e no município de Belo Horizonte.

PALAVRAS-CHAVE: Patrimônio Cultural na Década de 1980. Patrimônio Cultural em Minas Gerais. Patrimônio Cultural e Democracia.

ABSTRACT: Popular and institutional movements have increased the number of public policies on heritage preservation during the 1980s in Minas Gerais, creating major changes in subsequent decades. This study presents these movements comprehensively, highlighting their achievements and how they improved with the help of academia and technicians, demonstrating how they have influenced the institutional policies at the state level and in the municipality of Belo Horizonte.

KEYWORDS: 1980s Cultural Heritage. Cultural Heritage of Minas Gerais. Cultural Heritage and democracy.

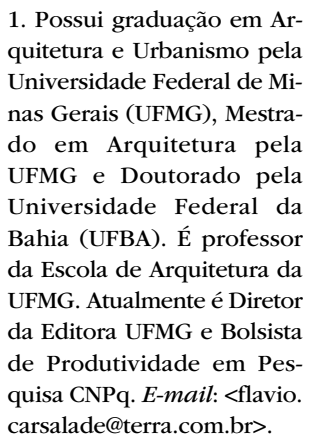
carsalade@terra.com.br>. 


\section{INTRODUÇÃO}

Este texto examina os movimentos populares e institucionais que redimensionaram as políticas públicas de preservação do patrimônio na década de 1980 e seus reflexos para as décadas seguintes, no estado de Minas Gerais. A primeira parte se dedica ao estudo dos anos 1980 e os avanços sociais na questão patrimonial, abordando (1) a situação política no estado de Minas Gerais e os órgãos patrimoniais; (2) os movimentos sociais de reivindicação ao direito patrimonial; e (3) a contribuição do campo técnico-científico. A segunda parte aborda os reflexos nas políticas públicas nas décadas subsequentes, 1990 e 2000, com o fortalecimento das ações municipais e das inovações nas políticas patrimoniais do estado de Minas Gerais e município de Belo Horizonte.

Essa abordagem foi estruturada pensando na importância de uma contextualização ampla, que contemple os movimentos sociais e o avanço do estado da arte na academia e nos quadros técnicos, para mostrar como eles influenciaram as reestruturações institucionais tanto no nível estadual quanto municipal.

\section{A DÉCADA DE 1980 E OS AVANÇOS SOCIAIS NA QUESTÃO PATRIMONIAL}

A situação política no estado de Minas Gerais e os órgãos patrimoniais

A década de 1980 foi marcada pela atuação dos movimentos populares que buscavam a redemocratização do país após a Ditadura Civil-militar, que já vinha acenando para seu próprio fim. Entre esses movimentos está aquele que uniu todo o país por eleições para presidente, as "Diretas Já!".

Durante a Ditadura Civil-militar brasileira (1964-1985), o crescimento exponencial das cidades já manifestava as injustiças sociais na distribuição de seu território e nas precárias condições de habitação e mobilidade, dentre outras, a que estavam submetidas grandes parcelas de seus moradores. $\bigcirc$ modelo de ocupação do território brasileiro já vinha sendo substituído do rural para o urbano, com um significativo êxodo rural que, a partir do século XX até os dias de hoje, fez com que chegássemos a uma cifra de mais de $80 \%$ da população concentrada nas cidades. ${ }^{2}$ Fato notável especialmente nas grandes metrópoles, sendo vertiginoso o crescimento das sub-habitações em vilas e favelas, resultantes da crônica concentração e má distribuição de renda no país. 
Em termos de planejamento urbano, o legado do período ditatorial no Brasil é marcado pelo duo imposição e tecnicismo. No período entre 1964 e 1988 lano da nova Constituição brasileira, a primeira após a redemocratização do país), as decisões foram tomadas em gabinetes, sem a participação popular e comandadas por interesses das classes dominantes. Era natural, portanto, que a resistência intelectual, dos técnicos e das lideranças mais esclarecidas do país, propugnasse por uma reforma na gestão urbana mais voltada para as questões sociais e por cidades mais equilibradas. Mesmo com os avanços constitucionais, mas ainda devido a grandes resistências dos setores mais conservadores, os direitos urbanos só se veriam consolidados como prática efetiva após treze anos da promulgação da "Constituição Cidadã" de 1988. Foi com a lei denominada "Estatuto da Cidade", de 10 de julho de 2001, que o princípio da gestão democrática das cidades suplantou as práticas autoritárias e tecnicistas que caracterizaram a realidade brasileira na Ditadura Civil-militar e mesmo no interregno entre a Constituição de 1988 e a promulgação do referido estatuto.

Os movimentos sociais urbanos tiveram grande impulso já no começo do século XX no Brasil, inicialmente como movimentos reivindicatórios de escala local, de vizinhança ou de bairro, em um tom ainda de "humilde solicitação". Nos anos 1970, começaram a se estruturar como movimentos mais organizados, onde se destacam aqueles ligados à moradia (nas várias associações - tais como as Associações de Amigos de Bairro) ou à lgreja Católica (as Comunidades Eclesiais de Base). Ao final dessa década e durante os anos 1980, as lutas se ampliaram para temas diversos como saneamento básico, meio ambiente, transportes, e as associações também começaram a se apresentar mais politizadas e articuladas entre si.

Algumas associações de bairro também receberam forte influência de um movimento rural chamado Movimento dos Sem Terra (MST), que reivindicava a redistribuição de terras improdutivas e uma efetiva reforma agrária no país. Dessa relação, surgiu nas principais metrópoles brasileiras o Movimento dos Trabalhadores Sem Teto (MTST), cuja principal estratégia de luta consistia na ocupação de prédios e terrenos vazios e subutilizados para forçar o início das negociações pró-moradias com governos e proprietários. Essas ocupações, verdadeiras práticas políticopedagógicas e de socialização, consistiam em ações planejadas e organizadas pelos militantes em um genuíno "processo de construção de sujeitos", os quais, embora ancorados em um objetivo específico, apontavam para uma ampla agenda de luta social. ${ }^{3}$ Segundo Santos, entre 1981 e 1984 em São Paulo, foram realizadas 65 ocupações (dezoito delas em áreas particulares com 9.358 famílias) e só em 1987, registraram-se 222 ocupações com 32 mil famílias. Em Recife, entre
3. Souza; Rodrigues (2004, p. 98). 
4. Santos (2004, p. 133, 136).

5. Souza; Rodrigues (2004, p. 12).

6. Santos (2004, p. 27). os anos de 1977 e 1981, foram sessenta ocupações e em Salvador, até 1981, 150 ocupações, especialmente em terras urbanas. ${ }^{4}$

Nesse mesmo período também surgiram e amadureceram as Organizações Não Governamentais (ONGs), que, de uma forma ou de outra, se associaram aos movimentos sociais para apontar outras possibilidades para o planejamento urbano graças ao "papel potencial dos próprios ativismos como 'planejadores', como protagonistas de um planejamento alternativo ao planejamento oficial e conservador". ${ }^{5}$ Esses ativismos geraram iniciativas de gestão mais democrática das cidades através de diferentes ações, como órgãos colegiados de política urbana, nos níveis nacional, estadual e municipal; debates, audiências e consultas públicas; conferências sobre assuntos de interesse urbano, nos níveis nacional, estadual e municipal e da iniciativa popular de projeto de lei e de planos, programas e projetos de desenvolvimento urbano. Essa forma de participação se desenvolveu em paralelo à tradicional organização tripartite do Estado baseada nos poderes executivo, legislativo e judiciário.

Os movimentos ligados ao meio ambiente apresentaram, como é característica desse setor, uma grande amplitude de causas com uma diversidade de bandeiras. Em Minas Gerais, destaca-se a questão da mineração por ela constituir um poderio econômico que consegue se manter à parte dos planos urbanos e de uma legislação mais limitadora, apresentando vários problemas, especialmente no que tange às dimensões da sustentabilidade e às relações com o universo social e cultural onde se instalam. A mineração em Minas Gerais responde por mais de $45 \%$ do produto mineral nacional, e a cadeia produtiva mineral responde por mais de $35 \%$ do Produto Interno Bruto (PIB) do estado, o que gera um poder político demasiadamente forte em favor do lobby da atividade mineradora. Este poder tem como consequência uma grande disputa entre os interesses das empresas de mineração e os da sociedade civil, representada principalmente por seus setores organizados, sob a bandeira da defesa do meio ambiente e dos grupos sociais mais afetados pelas ações mineradoras. Assim, esses movimentos de reação aos impactos causados pela mineração ajudaram a aglutinar as pessoas e a gerar movimentos reivindicatórios ainda incipientes nos anos 80, mas que colaboraram no amálgama do esforço coletivo de luta pela cidadania.

Por essas gêneses e por suas características, alguns autores consideram que "Os novos movimentos urbanos estariam mais vinculados à ampliação dos direitos da cidadania do que aos compromissos com as mudanças estruturais das relações capitalistas" no Brasil, onde inclusive se verificaria um deslocamento conceitual, com o conceito de "classe social" sendo substituído pelo de "comunidade", este, de certa forma, mais concreto porque calcado nas questões de "identidade" (como 
soma de significados compartilhados coletivamente) e de "experiências" (compartilhadas com relação aos bens comuns).

Essas questões remetem naturalmente para o campo da cultura onde, através de seus próprios instrumentos de expressão, canalizam um importante ativismo urbano, que

Além de lutar por melhorias materiais, os ativismos abriram a perspectiva de se pensar a identidade das pessoas como moradoras, levantaram questões sobre a cultura produzida nas favelas e periferias, enfim trouxeram para o debate temas ligados à subjetividade, à identidade e à cultura, dimensões extremamente importantes da vida humana que não podem ser desconsideradas ou simplesmente colocadas em segundo plano.?

Se hoje já temos formas mais contundentes desse ativismo no Brasil, tais como o movimento hip hop e seus subprodutos, o rap (rythm and poetry e seus congêneres como o funk e o encontro de $M C^{\prime}$ 's e DJ's), o break (a dança de rua) e o grafitti (arte urbana); nos anos 1980, a busca de identidades específicas parecia ser o norte da época, quando, por exemplo, a Música Popular Brasileira viu nascer gêneros alternativos como o sertanejo, o rock nacional, o pagode, dentre outros. A arte buscava seus regionalismos e novas formas de expressão. Em Minas Gerais os artistas buscavam um experimentalismo, comprometidos com o fazer e o explorar, todos com profundas raízes no cotidiano do povo mineiro e de sua terra, ou como disse Aracy Amaral:

E de algum tempo para cá, vem do fato de se poder distinguir a arte de Minas, tão peculiar entre as manifestações plásticas do Brasil de nosso tempo. E por que é singular? Porque nos artistas mineiros emerge com frequência como constante o cotidiano, o dado intimista, o sentido de uma tradição religiosa, um pouco em todos embora mais em alguns [...] extravasa o uso "do quintal", espaço da intimidade familiar, do lazer familiar - em festas, almoços ou simples reuniões de amigos, em que a conversa descontraída flui fácil - mas espaço igualmente do trabalho, espaço para o "fazer coisas". Inclui-se aí o trabalho manual, o conserto, o aproveitamento de materiais, o artesanal, e aqui a possibilidade de "invenção", e finalmente a própria criação artística que nasce organicamente, poderíamos dizer, dentro de um espaço que the é próprio. Espaço natural, seu, como a língua, a religião, a culinária, o comportamento enfim. ${ }^{8}$

A "cultura" deixava de ser, portanto, um atributo das elites e ganhava uma conotação de diversidade identitária mais definida. Um exemplo disso é o hip hop que, como ativismo social urbano, extrapola a sua linguagem específica e colabora para a expansão da consciência política, rompendo com a setorialidade que caracteriza as manifestações segmentadas:
7. Souza; Rodrigues (2004, p. 94).

8. Amaral (2000, p. 13-14). 
9. Souza; Rodrigues (2004, p. 102-102).

10. A Lei Federal 6.766 que regulamenta o parcelamento do solo urbano é de 1979, portanto posterior ao primeiro grande boom de muitas cidades de grande e médio porte brasileiras.
Vale a pena salientar que esse tipo de produção cultural rompe com a artificial divisão da vida social em cultura, economia, política, estética etc.: quando o hip-hop se apresenta como um movimento político-cultural, ele rompe claramente com tais divisões e põe a arte e a cultura fora de uma "esfera" responsável pela criação de obras "apolíticas" e alienadas que devem ser consumidas como produtos culturais e artísticos que visam o entretenimento, a contemplação, a reflexão e o "enriquecimento cultural" - como se essas ações estivessem dissociadas da política e da economia. A cultura perpassa a política e ambas tornam-se um único movimento. Cultura como política e política da cultura: essa é uma das características fundamentais e mais ricas do hip hop. ${ }^{9}$

Resgata-se, assim, através da dimensão cultural, uma importante forma de apropriação das cidades e do direito à sua fruição.

No caso específico do patrimônio cultural, as cidades brasileiras, a partir da década de 1980, passaram também a reivindicar o direito à memória. Os centros históricos brasileiros, a exemplo de similares em diferentes partes do planeta, passaram por graves problemas de deterioração causados pela monoespecialização funcional e por seu abandono pelas classes de maior poder aquisitivo que deixaram de habitar esses locais. Além disso, conforme vimos anteriormente, o crescimento abrupto das cidades brasileiras foi realizado em grande parte em um período em que a legislação urbanística ainda não era abrangente e suficiente, ${ }^{10} \mathrm{em}$ que as perversidades das desigualdades sociais ainda não eram tão claras para grande parte da população e em um momento onde os problemas de habitação eram resolvidos pelos técnicos, empurrando os mais pobres para as periferias urbanas. As áreas centrais das cidades não eram tão valorizadas ainda na sua importância simbólica, por um entendimento "curto" da ideia de patrimônio cultural ligado essencialmente à excepcionalidade histórica e artística, desprezando abordagens culturais mais amplas relacionadas à apropriação popular dos centros urbanos, quer do ponto de vista material (uso) quanto imaterial (simbólico) e das inter-relações entre essas duas formas de apropriação.

Embora a maioria das cidades brasileiras de médio e grande porte tivesse sua paisagem desfigurada, as grandes cidades foram as que mais sacrificaram suas áreas centrais face ao "modelo" de desenvolvimento urbano brasileiro. Isto se deu exatamente por essas áreas apresentarem, de um modo geral, uma maior infraestrutura instalada (e, dessa maneira, necessitarem de menor investimento público), por serem altamente polarizadoras (e, em vista disso, mais pressionadas, nos seus edifícios e em suas vias) e por serem mais suscetíveis à concepção urbana funcionalista, que marcou a maior parte do século XX e que thes estimulava um papel principal de centro comercial e de serviços. É curioso que essas mesmas razões tenham causado tanto o abandono das áreas centrais que muito se alteraram (por intenso processo de destruição e substituição), quanto daquelas que não se alteraram, mas apenas se 
degradaram. De uma maneira geral, exceto em alguns casos pioneiros, tal situação só começou a se reverter na última década do século arravés de uma intensa revisão dos paradigmas de planejamento urbano até então vigentes.

A política de preservação do patrimônio histórico e artístico no país já vinha se consolidando desde 1937 com a criação de uma lei federal de preservação e pela ação do Instituto do Patrimônio Histórico e Artístico Nacional (lphan), que veio ganhando prestígio por sua luta na preservação, principalmente, de nossa herança colonial representada pelas cidades históricas" de Minas Gerais e pelos centros históricos de cidades litorâneas do mesmo período. Foi graças a essa incipiente consciência de preservação que, apesar da ditadura e das dificuldades econômicas e talvez até por seu caráter mais ligado à conservação do que a causas mais "progressistas" ou "revolucionárias", que os governos procuraram criar mecanismos para sua efetivação.

Nas principais cidades do país, a partir especialmente dos anos 1960, após a "leva" inicial de tombamentos das "cidades históricas" no início da ałuação do Sphan (Serviço do Patrimônio Histórico e Artístico Nacional) na década de 1930, começaram as pressões para estancar as degradações dos edifícios e espaços públicos urbanos que apresentassem caráter histórico, evocando-se o direito à memória e ligando a preservação cultural à própria preservação ambiental. Nesse segundo momento de salvaguarda, na década de 1970, através de uma visão meramente economicista, os esforços eram para garantir o retorno dos investimentos feitos na conservação do patrimônio através do turismo.

Um dos maiores planos brasileiros, o da recuperação da região do Pelourinho na cidade de Salvador, apresentou um modelo de acentuada intervenção governamental, alto nível de investimento público na sua recuperação, uma gestão fortemente dependente de subsídios governamentais e a expulsão maciça da população residente em uma gentrificação sem precedentes no país. Tudo isso, é claro, sem nenhuma participação popular.

Com a redemocratização do país cresceram as reivindicações locais pelo direito à memória e, pós-Constituição de 1988, com a ênfase por ela dada às municipalidades, começaram a nascer os conselhos municipais de preservação de seu patrimônio local, os quais passaram a ser o palco dos embates entre interesses pró e contra as proteções. A Constituição também reconheceu o direito à memória e ao patrimônio como um direito difuso da sociedade, adotando a ampliação do conceito de patrimônio cultural vindo do aporte antropológico, e, em seus artigos 215 e 216, garante a todos "o pleno exercício dos direitos culturais", "acesso às fontes da cultura nacional", "valorização e difusão das manifestações culturais".
11. Nome genérico dado às cidades com tombamento federal e/ ou estadual, célebres por seu patrimônio histórico edificado e por sua morfologia urbana, geralmente ligadas ao século XVIII, tais como Ouro Preto, Mariana, Diamantina, entre outras. 
Em Minas Gerais, o primeiro governo eleito durante o processo de abertura da Ditadura Civil-militar foi o de Tancredo Neves, em 1982, partir do qual ele se elegeu Presidente da República ainda em pleito indireto. Embora já soprassem novos ventos, os governos estaduais e municipais da década de 1980 ainda não haviam incorporado as novas práticas sociais e, pelo menos em Minas Gerais, viam o patrimônio como uma ameaça ao direito de propriedade e "obstáculo" aos avanços econômicos e ao desenvolvimento. Essa caracterização era acrescida pelas práticas dos defensores dos patrimônios em conselhos municipais, por exemplo, pois ameaçavam o poder decisório ainda muito centralizado. $\bigcirc$ órgão estadual do patrimônio mineiro - o Instituto Estadual do Patrimônio Histórico e Artístico do Estado de Minas Gerais (lepha-MG) - foi sucateado durante essa década e teve sua autonomia desrespeitada em vários episódios, como se verá adiante.

\section{A reivindicação ao Direito Patrimonial e os movimentos sociais em Minas Gerais}

Minas Gerais é um dos estados brasileiros mais aquinhoados com a patrimonialização federal, em parte devido ao fato de que a gestação do DecretoLei 25 de 1937, feita pelos intelectuais modernistas, tinha reconhecido por aqui o berço de uma cultura eminentemente brasileira, "antropofagicamente" resultante da miscigenação étnica. No entanto, esta proteção se dirigia para monumentos civis e religiosos ligados a um momento específico da história brasileira: o período colonial. E, embora protegendo núcleos urbanos inteiros, não conseguia abranger o enorme acervo de mesmas épocas e tipologias, pois suas categorias eram restritas, deixando a descoberto a grande imensidão do estado.

Consciente disto, na década de 1970, o Iphan estimulou os estados a criarem seus próprios órgãos patrimoniais e a partir de um compromisso entre governadores nasceram vários desses órgãos, como o lepha, fundado em 1971. Toda a institucionalização da entidade mineira se espelhou no Iphan, incluindo a estruturação de suas diretorias e a existência do Conselho Curador, bem como a legislação e ritos de proteção. Este espelhamento era tão forte que até os objetos de ação eram os mesmos: os seus esforços iniciais se dedicaram à proteção daqueles exemplares do período colonial mineiro não cobertos pelo Iphan, aqui conhecidos como "barroco estradeiro". Também foram tombados núcleos urbanos como Santa Rita Durão, São Tomé das Letras, dentre outros, nos moldes da instituição-mãe.

Já na sua gênese, o órgão estadual procurou não sobrepor suas ações às do órgão federal, optando por uma atuação complementar, o que explica a sua 
pouca presença nas mais famosas cidades históricas mineiras. De forma ampla, procurou criar uma política própria, protegendo aqueles bens que julgava representativos da cultura mineira e só atuando nos municípios quando algum bem importante para eles, na falta de uma política de patrimônio local, se encontrava grandemente ameaçado. Procurava até mesmo não se envolver com as prefeituras, mesmo quando se tratava de seus próprios núcleos históricos tombados a nível municipal, onde uma articulação entre entes federativos fosse altamente desejável.

Embora alguns núcleos e edificações ecléticas se agregassem à sua lista de bens protegidos, mudanças realmente grandes na abrangência e na orientação de políticas públicas de patrimônio só viriam a ocorrer no final da década de 1990 e mesmo assim como subproduto de uma lei de redistribuição tributária do Imposto sobre Circulação de Materiais e Serviços (ICMS). Esta lei, que ficou conhecida como "Lei Robin Hood", modificou fortemente os processos de tombamento, assim como as relações entre estado e municípios, após ser apropriada com muita perspicácia pelo setor do Patrimônio Cultural. Como se vê, a criação do órgão estadual foi antes uma ação de cima para baixo que fruto de reivindicações populares, muito devido ao ano de seu surgimento, 1971, só passando a incorporar as lutas de reivindicação duas décadas depois.

A realidade de Belo Horizonte, no entanto, já se configura de maneira diversa quanto à criação de seu sistema de proteção patrimonial municipal, baseado em vários movimentos de luta popular pela sua implementação. Para melhor compreender esse processo, é interessante mostrar um pouco da história da cidade e como estas lutas nela se inserem.

A capital de Minas Gerais, Belo Horizonte (BH), foi inaugurada em 1897 e nasceu como a primeira cidade planejada da recém-criada república brasileira (1 889), sob a égide do positivismo científico e da celebração dos valores civis, em tudo oposta a Ouro Preto, cidade colonial ligada ao ciclo do ouro, que até então havia sido sua capital. Seus edifícios públicos, construídos pela inspiração neoclássica do ecletismo estilístico, exaltavam em sua ornamentação os valores da República e da democracia. Seu crescimento foi exponencial, em 1920 com apenas 23 anos, a cidade já contava com 55.000 habitantes e em 1930 com 140.000. Desde então começou a aparecer aquela que seria uma característica de Belo Horizonte: a exclusão social da zona central, aspecto compartilhado por outras metrópoles brasileiras.

O surto desenvolvimentista das décadas de 1930 e 1940, conjugado com o aumento populacional da capital, consolidaram o hipercentro da cidade através de uma incessante substituição de edificações antigas - se é que se pode chamar de antigas as edificações construídas poucas décadas antes - por edifícios verticais. A este impulso desenvolvimentista somava-se a ideia de que a cidade nascera para ser 
moderna, o que foi reforçado no início da década de 1940, período da administração de Juscelino Kubitschek, no qual ele demonstrou o mesmo espírito que marcaria sua gestão como presidente do Brasil entre 1957 e 1960. Kubitschek incentivou a industrialização e a modernização da cidade e se dedicou a um projeto ambicioso: a Pampulha, onde é marcado o início da modernidade arquitetônica brasileira com a obra seminal do arquiteto Oscar Niemeyer e do paisagista Burle-Marx.

A pressão populacional associada à atratividade econômica continuou transformando a paisagem de BH nas décadas de 1950 e 1960, com a construção de edifícios comerciais e residenciais especialmente destinados à população de renda média-alta em sua zona central, e a geração de vazios urbanos, muitos dos quais foram ocupados por favelas ou outros tipos de urbanização não projetadas ou surgidas pela especulação imobiliária. Para se ter uma ideia, a população de $\mathrm{BH}$ era, em 1950, de aproximadamente 350.000 habitantes. Em 1960 duplicou seu número (700.000 habitantes) e em 1970 praticamente voltou a duplicar (1 .200.000 habitantes). Por essa época, cerca de 10\% da população já vivia em favelas.

As altas taxas de crescimento urbano e a concentração do poder a partir do Golpe de 1964 criaram o clima propício para a centralização de algumas funções urbanas, como habitação e transporte, fazendo com que diretrizes tecnocráticas de grandes instituições nacionais - como o Banco Nacional de Habitação e a Companhia Brasileira de Trens Urbanos - preponderassem sobre as diferenças regionais. Essa centralização setorial acabava por causar uma dispersão de decisões entre os três entes federativos quanto ao planejamento urbano dos municípios, onde já se constatavam deficiências face ao crescimento urbano explosivo, ocorrido entre 1976 e 1996. No nível local, um planejamento metropolitano forte também se impôs às aspirações das cidades vizinhas a $\mathrm{BH}$. Na Região Metropolitana de Belo Horizonte este planejamento se efetivou pela ação do Plambel (Superintendência de Desenvolvimento da Região Metropolitana de Belo Horizonte).

Assim, com a zona central praticamente ocupada em sua totalidade, nas décadas de 1970 e 1980 presenciou-se um processo contínuo de substituição de edifícios ou de seus usos, devido, especificamente, à especulação imobiliária, sem nenhuma consideração à paisagem urbana ou a valores histórico-culturais. Estimulada pelos altos índices de aproveitamento, a ocupação do centro se verticalizou e adensou, destruindo assim importantes referências simbólicas para a população de $\mathrm{BH}$. Duas dessas intervenções impulsionaram os movimentos de preservação do patrimônio na cidade: o primeiro, as transformações na Praça da Estação para acolher os projetos da estação para trens urbanos e, na mesma quadra do edifício da Prefeitura, a demolição do Cine Metrópole (antigo Teatro Municipal) transformado em um edifício em cuja base se instalou uma agência bancária. Desses dois episódios 
nasceu a legislação municipal de defesa do patrimônio histórico que experimentou suas primeiras posturas nos últimos anos da década de 1980, mas que só se consolidou como política pública a partir de 1992.

As diversas interferências urbanas que ocorreram na área central de Belo Horizonte, causadas por legislações urbanísticas ou planos viários, reforçaram essas mutilações por terem como foco apenas as questões funcionais e de desenvolvimento econômico, colocando em segundo plano a paisagem, os ritmos e os ritos urbanos, como se isso fosse uma consequência inexorável da modernidade. A Lei de Uso e Ocupação do Solo de Belo Horizonte, de 1976 - praticamente a primeira da capital, antes legislada por outros instrumentos urbanísticos como códigos de obras e leis menores -, reforçava a visão funcionalista da cidade e colocava os maiores coeficientes de aproveitamento de solo urbano exatamente nos lotes ocupados por importantes exemplares da nossa memória (como as casas do bairro Funcionários). Os projetos viários estreitavam ruas e fechavam quarteirões mais preocupados com a ótica da mobilidade do automóvel do que com o significado simbólico das vias e com sua apropriação pela população. Sorte que a função residencial foi preservada no centro, mera casualidade histórica. $O$ grande impacto na área central de Belo Horizonte ainda foi agravado por suas características geográficas e socioeconômicas: fortemente marcada pela radiocentricidade, onde a maior parte das vias e deslocamentos necessariamente cruza o centro da cidade e onde, durante muito tempo, concentraram-se a maioria dos serviços de atendimento à população e a maioria dos eventos de interesse.

Em nome deste ímpeto desenvolvimentista e da força do capital, várias descaracterizações ocorreram na cidade, como a redução drástica do perfil da Serra do Curral, resultado da sanha mineradora; a redução dos adros e jardins das igrejas, muitas delas importantes referências da cidade (como os jardins da Igreja São José, substituídos por edifícios comerciais em 1976) ou de bairro (como os jardins da Igreja Nossa Senhora das Dores do bairro Floresta, nos anos 1970, substituídos também por lojas). As denúncias da sociedade começaram a ocorrer e seu libelo mais conhecido foi o poema Triste Horizonte (1978), onde o poeta Carlos Drummond de Andrade denunciava a destruição da memória da cidade:

\section{$[\ldots]$}

Esquecer, quero esquecer é a brutal Belo Horizonte

que se empavona sobre o corpo crucificado da primeira.

Quero não saber da traição de seus santos. 
Eles a protegiam, agora protegem-se a si mesmos.

São José, no centro mesmo da cidade,

explora estacionamento de automóveis

São José dendroclasta não deixa de pé sequer um pé-de-pau

onde amarrar o burrinho numa parada no caminho do Egito.

São José vai entrar feio no comércio de imóveis,

vendendo seus jardins reservados a Deus.

São Pedro instala supermercado.

Nossa Senhora das Dores,

amizade da gente na Floresta,

(vi crescer sua igreja à sombra do Padre Artur)

abre caderneta de poupança,

lojas de acessórios para carros,

papelaria, aviário, pães-de-queijo

$[\ldots]^{12}$

caso da Serra do Curral, símbolo de Belo Horizonte, foi tão grave que motivou um tombamento federal pelo Iphan em 1961, na medida em que o estado não conseguia (ou não queria) se indispor com as mineradoras. A situação de destruição da serra já se tornava insustentável e gerou vários movimentos populares simbolizados pela ampla distribuição de um adesivo para automóveis com os dizeres "Olhe bem as montanhas" de autoria do artista plástico Manfredo Souzanetto. Os efeitos do tombamento foram muito pequenos, talvez pela ausência de uma regulamentação e fiscalização adequadas, e a ação das mineradoras continuou forte, respeitando o perfil remanescente, mas destruindo terrenos de cotas mais baixas.

A reação popular em Belo Horizonte, inicialmente tênue e particularizada, passou a se tornar causa de maiores segmentos da população a partir de dois grandes movimentos, descritos aqui com maior detalhe, em razão dos objetivos deste artigo: o movimento em defesa da Praça da Estação e o de defesa do Cine Metrópole.

A ferrovia teve papel proeminente na cidade de Belo Horizonte - assim como em várias cidades mineiras e brasileiras através de seu papel "civilizatório" de criação de cidades - mas, com a sua substituição pelo rodoviarismo, sofreu acentuado declínio a partir da segunda metade do século XX, chegando a ser desativada a 
função de transporte de passageiros nas suas últimas três décadas. Na capital mineira, a Praça da Estação se constituiu como porta de entrada da cidade e como importantíssima referência urbana, não só associada às suas origens mas também ao seu papel agregador da população e de grande largo urbano, onde historicamente se realizaram as grandes manifestações de cidadania. Fora também lugar de instalação de várias fábricas e instituições municipais e, em seu entorno, nasceram outros importantes marcos urbanos representados na forma de edificações la própria estação, o Edifício Chagas Dória, a Escola de Engenharia da UFMG, dentre outras) e espaços públicos (Viaduto Santa Tereza, jardins da praça). Complementam o conjunto um rico acervo de casas particulares (em seu entorno imediato e no bairro Floresta, a ela adjacente), a própria Rede Ferroviária Federal (RFFSA) e situações urbanas ímpares, como o grande terraço em belvedere constituído pela rua Sapucaí.

No início dos anos 1980, a sociedade sentiu a ameaça da perda da grande memória ali constituída, representada pela iminência de implantação do metrô de superfície através de um órgão gerido desde Brasília, a Companhia Brasileira de Trens Urbanos (CBTU). O projeto visava aproveitar os trilhos existentes para a rolagem dos vagões de transporte de massa da cidade - o que se efetivou - e a realização de várias obras complementares, inclusive a da grande estação central desse metrô. A possibilidade de destruição da ambiência local motivou várias reações, sendo a mais contundente a do Instituto de Arquitetos do Brasil Departamento Minas Gerais (IAB-MG) que conseguiu mobilizar a sociedade civil, o mundo acadêmico, o poder público e várias instituições em torno de um seminário cujo objetivo resultaria em ações concretas de preservação. Assim, foi realizado o I Encontro Praça da Estação: origem e destino, entre os dias 12 e 20 de agosto de 1981, onde a principal moção aprovada apresentava o seguinte teor:

Que seja solicitada ao Prefeito de Belo Horizonte a edição de uma portaria para a institucionalização de uma Comissão, em caráter permanente, integrada por organismos públicos de planejamento e execução de obras, pela Escola de Arquitetura, Instituto de Arquitetos do Brasil e outros representantes da sociedade civil, com o objetivo de defender as linhas básicas de uma política de preservação para o Município, considerando aspectos relativos ao seu patrimônio histórico, cultural e artístico. ${ }^{13}$

Sugeriu-se ainda que os prédios a serem preservados na Praça, na medida do possível, fossem transformados em centros de atividades culturais. Mas as ações meramente locais foram ampliadas pela preocupação com a ausência de uma política adequada de preservação do patrimônio na capital, sendo sugerida a criação de uma Comissão Municipal de Tombamento, sob a presidência do
13. Cf. Instituto dos Arquitetos do Brasil - Minas Gerais (1981). 
secretário municipal de cultura, turismo e esportes, além da criação da Fundação Municipal de Cultura. Apesar da concordância praticamente unânime dos órgãos em acatar as decisões do seminário, pouco ou quase nada foi feito. Na administração do prefeito Júlio Laender, sob a coordenação do Departamento de Cultura, da Secretaria Municipal de Turismo, Esporte e Cultura, foi formada uma comissão, com participação de instituiç̧ões como IAB, Plambel, lepha, Museu Abílio Barreto, UFMG e as secretarias municipais de Serviços Urbanos e de Obras, entre outras.

No entanto, o que realmente se efetivou, à falta de uma legislação local de proteção ao patrimônio, foi uma lei municipal, em anexo à Lei de Uso e Ocupação do Solo de Belo Horizonte (1985), a qual definia o perímetro da Área de Proteção do Conjunto da Praça Rui Barbosa, além do tombamento estadual da praça pelo lepha em 1988. Apesar desta proteção estadual e dos clamores da população pela criação de um serviço municipal de defesa do patrimônio cultural, o Executivo e o Legislativo municipais não deram imediata continuidade à ação exigida no I Encontro Praça da Estação: origem e destino, deixando vários outros exemplares imóveis da história da cidade a descoberto, sendo muitos deles demolidos no intervalo entre este episódio e a efetiva criação do serviço no município, incluindo o Cine Metrópole.

Construído inicialmente como Teatro Municipal (1906) em estilo eclético, foi reformado ao final doas anos 1930, em feições art decó. Na administração Juscelino Kubitscheck, considerado insuficiente para um teatro municipal à altura da cidade, o edifício que receberia o Cine Metrópole foi colocado em hasta pública com o objetivo de se angariar fundos para a construção de um novo (projetado por Oscar Niemeyer no Parque Municipal, hoje Palácio das Artes). O leilão foi arrematado por um empresário que o transformou em cinema, que permaneceu ativo entre 1942 e 1983, conquistando grande espaço afetivo entre a população belo-horizontina e enorme significância como espaço cultural em uma cidade até então muito carente desse tipo de atividade, apesar da existência de outras grandes salas de cinema localizadas em seu centro. Um dos aspectos da sua referência especial era sua localização na rua da Bahia, notável pelos movimentos culturais ao longo de toda a sua história e cantada por Carlos Drummond de Andrade e Pedro Nava.

Em 1983, com o fechamento do cinema, seu proprietário iniciou um processo de venda para o Banco Bradesco visando a construção de um edifício comercial de vários pavimentos no local. $\bigcirc$ fato consternou uma parte significativa da população da cidade que passou a exigir o tombamento do cinema. Dois aspectos desse caso são notáveis: o desprezo com a questão processual e os aspectos teóricos da preservação.

Quanto à questão processual, houve uma série de idas e vindas, desde o anúncio da venda do imóvel em abril de 1983 até a sua demolição, em julho do mesmo ano, com evidente intenção de manipular para que o tombamento não 
se efetivasse. $\bigcirc$ governo Tancredo Neves determinou a elaboração de um decreto de utilidade pública para o imóvel (22 de abril); o pedido de demolição foi negado (27 de abrill); o prédio foi tombado provisoriamente pelo Conselho Curador do lepha e em seguida definitivamente (3 de maio), sendo encaminhada ao governador a homologação. Pouco depois, uma manifestação de estudantes que apoiavam o tombamento foi reprimida duramente (17 de maio); o proprietário pediu a impugnação do tombamento ( 18 de maio), que foi negado em reunião do Conselho (26 de maio); o cinema, que ainda se encontrava em funcionamento, foi fechado (27 de maio). Em seguida, o Governo do Estado ignorou a competência do Conselho e criou uma Comissão Especial para examinar os méritos do tombamento (28 de maio); diante do desrespeito ao lepha, sua presidente, Prof. Suzy de Mello, pediu ao governador que fizesse o tombamento por decreto ignorando a absurda Comissão Especial (31 de maio); o edifício começou a ser demolido com a retirada de suas poltronas e o lepha notificou seus proprietários ( 10 de junho); a demolição continuou e o lepha solicitou apoio à Procuradoria Geral (13 de junho). Diante da continuidade das obras, a presidente recomendou o seu destombamento em vista das descaracterizações sofridas - desde que o proprietário fosse penalizado com a construção de novo prédio para o cinema - e, imediatamente, pediu sua própria demissão 13 de julho). A Comissão Especial aceitou as ponderações da presidente demissionária e encaminhou tal decisão ao governador (21 de julho), ele acatou a recomendação e não homologou o tombamento, na prática, destombando-o (23 de julho). A partir daí, começaram a elaboração do projeto e construção da nova sede do Banco Bradesco que até hoje lá se encontra. Todo o processo foi evidentemente desenvolvido para "justificar" sua demolição, desrespeitando a comoção popular e os ritos legais. Herança de tempos sombrios.

O debate público a respeito do caso também é digno de nota por retratar o estado das discussões teóricas sobre a preservação patrimonial. Aqueles que defendiam sua demolição (com acadêmicos e técnicos do patrimônio incluídos nesse grupo), argumentavam pela descaracterização do edifício, por se tratar de um estilo espúrio (iá que as feições ecléticas foram metamorfoseadas em decó), que tanto o estilo eclético quanto o decó não tinham importância para a história da arquitetura de Belo Horizonte por serem "importados" e banais, e que a herança arquitetônica a se orgulhar seria o barroco mineiro presente nas cidades históricas. Estes eram rebatidos por aqueles que defendiam a preservação, apontando que no Brasil, afora as construções indígenas, todos os estilos eram importados, que na história da arquitetura não havia estilos mais ou menos importantes, mas que todos eles retratavam períodos históricos e diziam, um pouco avant la letre, que 
independentemente das questões estilísticas, o seu significado para a população e a sua presença urbana, associados à sua função cultural, justificavam sua permanência. A sociedade estava em transição. Os debates já apontavam para uma mudança importante no entendimento sobre a preservação do patrimônio cultural, naquele momento muito voltado para a proteção de monumentos isolados e segundo critérios estritos de excepcionalidade, para uma visão mais ampla de patrimônio que buscaria abranger também a questão urbana e a exemplaridade dos bens, além da excelência estilística e dos bens do Estado ou da lgreja.

Eventos emblemáticos como estes se associaram às recomendações da Constituição Federal de 1988 e, a partir da trilha aberta por ela, criaram também suas cartas magnas nos níveis estadual e municipal, com artigos e cláusulas específicas para a proteção da memória coletiva. Assim, a Constituição do Estado de Minas Gerais, promulgada em 21 de setembro de 1989, reza:

Art. 207 - O Poder Público garante a todos o pleno exercício dos direitos culturais, para o que incentivará, valorizará e difundirá as manifestações culturais da comunidade mineira, mediante, sobretudo:

$[\ldots]$

IV - adoção de medidas adequadas à identificação, proteção, conservação, revalorização e recuperação do patrimônio cultural, histórico, natural e científico do Estado;

$V$ - adoção de incentivos fiscais que estimulem as empresas privadas a investir na produção cultural e artística do Estado, e na preservação do seu patrimônio histórico, artístico e cultural;

VI - adoção de ação impeditiva da evasão, destruição e descaracterização de obras de arte e de outros bens de valor histórico, científico, artístico e cultural;

$[\ldots]$

Art. 208 - Constituem patrimônio cultural mineiro os bens de natureza material e imaterial, tomados individualmente ou em conjunto, que contenham referência à identidade, à ação e à memória dos diferentes grupos formadores da sociedade mineira, entre os quais se incluem:

I - as formas de expressão;

II - os modos de criar, fazer e viver;

III - as criações científicas, tecnológicas e artísticas;

IV - as obras, objetos, documentos, edificações e demais espaços destinados a manifestações artístico-culturais; 
V - os conjuntos urbanos e sítios de valor histórico, paisagístico, artístico, arqueológico, espeleológico, paleontológico, ecológico e científico.

$[\ldots]$

Art. 261 - É facultado a qualquer pessoa e obrigatório para o servidor público representar ao Ministério Público, quando for o caso, contra ato lesivo ao meio ambiente, ao patrimônio artístico ou histórico, ao turismo ou paisagismo e aos direitos do consumidor. ${ }^{14}$

Um dos importantes pilares da Constituição foi aquele relativo à questão da propriedade, submetendo a propriedade privada à sua função social. No caso do patrimônio cultural, seus reflexos seriam da seguinte ordem:

Partindo desse princípio, o direito à propriedade assegurado pela Constituição Federal não desvincula a propriedade da sua função social. Cabe, portanto, aos articuladores da política de proteção ao patrimônio cultural dizer em cada caso o que dá a certo bem a condição de patrimônio cultural, esclarecendo qual a função social que exerce através da sua referência cultural, do seu suporte da memória social e do que diz cada conjunto ou imóvel à cidade. ${ }^{15}$

Na sequência, a Lei Orgânica do Município de Belo Horizonte de 21 de março de 1990 também promulgava suas normas quanto ao patrimônio cultural:

Art. 167 - Constituem patrimônio cultural do Município os bens de natureza material e imaterial, tomados individualmente ou em conjunto, que contenham referência à identidade, à ação e à memória do povo belo-horizontino, entre os quais se incluem: I - as formas de expressão;

II - os modos de criar, fazer e viver;

III - as criações tecnológicas, científicas e artísticas;

IV - as obras, os objetos, os documentos, as edificações e outros espaços destinados a manifestações artísticas e culturais, nestas incluídas todas as formas de expressão popular; $\checkmark$ - os conjuntos urbanos e os sítios de valor histórico, artístico, paisagístico, arqueológico, paleontológico, ecológico e científico.

$\S 1^{\circ}$ - As áreas públicas, especialmente os parques, os jardins e as praças, são abertas às manifestações culturais, desde que estas não tenham fins lucrativos e sejam compatíveis com a preservação do patrimônio ambiental, paisagístico, arquitetônico e histórico.

[...]

Art. 168 - ○ Município, com a colaboração da sociedade civil, protegerá o seu patrimônio histórico e cultural, por meio de inventários, pesquisas, registros, vigilância, tombamento, desapropriação e outras formas de acautelamento e preservação.
14. Minas Gerais (2020, p 159-161, 186).

15. Azevedo; Botelho (2005, p. 46). 
16. Belo Horizonte (1990, p. 53).

17. Cf. Magni (2012).

18. Alguns parâmetros sugeridos pela Carta de Princípios (1990), iniciando pelo seu caput: "Entende-se como patrimônio cultural, dentro desta abordagem mais ampla, não apenas os bens móveis e imóveis já existentes no território municipal e cuja conservação seja de interesse público, mas também a potencialidade de geração do fato cultural, entendendo que o crescimento urbano deve também considerar este fato e a ele oferecer espaços adequados. Ao conceito de preservação de bens móveis e imóveis (memória histórica) há que se somarem também os conceitos de 'identidade' e 'apropriação do solo (uso e ocupação) como patrimônio cultural'. Este entendimento amplo de política de patrimônio torna a sua implantação urgente, posto que a divulgação de redução de gabaritos de ocupação pelo novo Plano Diretor está ocasionando, dada a uma incorreta informação dos proprietários, uma série de demolições indesejáveis. Daí não apenas a urgência de sua implantação, como também a sua incorporação à legislação vigente". Sugeria medidas que: (1) premiem o proprietário oferecendo-lhe compensações à preservação de seu imóvel; (2) incentivem a preservação; (3) preservem a instituição do tombamento, criando outras medidas protetivas; $\mathrm{e}$ (4) revertam o processo de destruição que sempre ocorre em épocas de mudanças de legislação. Sugeria também algumas diretrizes: (1) inventário; (2) proteção da memória histórica (imóveis anteriores a 1940); (3) tombamento de uso (no caso de substituição de imóveis culturais); (4) zoneamento cultural; (5)
Parágrafo Único - O Poder Público manterá sistema de arquivos públicos e privados com a finalidade de promover o recolhimento, a preservação e a divulgação do patrimônio documental de organismos públicos municipais, bem como de documentos privados de interesse público, a fim de que possam ser utilizados como instrumento de apoio à administração, à cultura e ao desenvolvimento científico e como elemento de prova e informação. ${ }^{16}$

Além disso, a Lei Orgânica do Município tombava vinte e quatro bens imóveis na cidade em seu artigo 224, mais tarde considerado inconstitucional conforme a Ação Direta de Inconstitucionalidade n 40.647-0, do Tribunal de Justiça de Minas Gerais. Antes dela, no entanto, os eventos em Belo Horizonte ensejaram duas tentativas de criação de mecanismos de proteção do patrimônio na cidade.

A primeira foi a Lei 3.640/1983, vetada pelo então prefeito Hélio Garcia que via nela entraves à propriedade privada e ao desenvolvimento socioeconômico do município. Já a Lei 3.082/1984 organizava o processo de patrimonialização em $\mathrm{BH}$, proposta pelo vereador Arthur Vianna em parceria com o IAB-MG e se distinguia pela inovação quanto ao caráter deliberativo do Conselho Municipal de Patrimônio Cultural, que tornava desnecessária a homologação pelo chefe do executivo para a efetivação de suas decisões (herança do caso Cine Metrópole). Ainda assim a lei foi questionada pelo próprio IAB que a considerava calcada apenas no instrumento do tombamento e não conseguia atuar no planejamento urbano. Embora a lei tenha sido promulgada, sua efetivação ainda demoraria alguns anos.

desenvolvimento de sua implantação, especialmente marcado pela atuação do Conselho Deliberativo Municipal do Patrimônio Cultural (CDPCM-BH) é narrado por Teodoro Magni que delimita quatro fases, ${ }^{17}$ através de sete mandatos municipais (sendo o primeiro deles, o de Sergio Ferrara, a partir de 1986).

Na fase "Imobilista fechada" (1986-1988), considerada assim por ser incipiente, pouco participativa, sem uma representação ampla da sociedade e restrita a alguns técnicos, políticos e personalidades especialmente convidadas, não houve tombamentos. $\bigcirc$ Conselho era formado por nove membros, todos de órgãos públicos.

Já durante a fase "Burocrática monumentalista" (1989-1992), a partir do governo Pimenta da Veiga, a composição do Conselho era mais técnica, institucional e interdisciplinar, sem participação popular. Nesta fase foram realizados os primeiros tombamentos, segundo a pauta da Secretaria Municipal de Cultura. Caracterizava-se por uma ausência de parâmetros específicos e de critérios, apesar da tentativa de elaboração de uma Carta de Princípios, ${ }^{18}$ redigida por um grupo de seus membros, 19 onde se esboçava a proposta de um zoneamento cultural que daria origem aos primeiros conjuntos urbanos tombados (no caso, o da Praça da Liberdade). 
A fase "Participativa ampliada" (1993-1999) foi caracterizada pela participação popular de maior visibilidade e pela ampliação das políticas de patrimônio centrada em ambientes urbanos e "patrimônio não consagrado" ou "produção dos excluídos". Seu momento mais marcante foi a grande proteção de conjuntos urbanos (1994), onde, de uma só vez, foram tombados centenas de imóveis na região central da cidade, seguido por uma etapa de negociações com os proprietários desses imóveis. Em alguns casos, o instrumento de tombamento foi flexibilizado por medidas atenuadoras, por exemplo o tombamento apenas de fachadas, ação considerada necessária para diminuir o forte impacto causado pelos tombamentos em massa e para a sobrevivência do ato. Em 1997, estes conjuntos protegidos seriam disciplinados pelas Diretrizes de Proteção dos Conjuntos Urbanos Tombados e pela institucionalização de uma política de "negociações urbanas".

Magni aponta que desde os anos 2000 configura-se uma fase de "Gestão e negociação", caracterizada pelo amadurecimento das políticas públicas e pela preocupação com a gestão do enorme acervo já protegido. A partir das Diretrizes de Proteção, o Conselho passa a examinar cada caso e admite flexibilizações desde que elas resultassem em ganhos qualitativos maiores do que as Diretrizes. Tais medidas atuavam diretamente sobre a ocupação do solo urbano nas áreas tombadas, fato que causou sucessivos embates com a Câmara de Vereadores que se via usurpada em sua competência constitucional de legislar sobre o solo urbano. Apesar disso, a ałuação do CDPCM-BH segue protegendo e qualificando esses espaços em um processo intenso de negociações urbanas.

Azevedo e Botelho ${ }^{20}$ enfatizam algumas características importantes do CDPCM-BH, que seriam seu caráter deliberativo, o qual reforçava seu papel de instância híbrida (quando a sociedade organizada atua junto ao poder público através de instituições representativas de interesses diversos); a quebra da prática monumentalista, com a priorização da proteção em conjuntos urbanos, alguns deles de caráter popular; e a prática das "negociações urbanas", onde as diretrizes estabelecidas para os conjuntos arquitetônicos poderia ser flexibilizada a partir da percepção de que melhores resultados seriam alcançados através de propostas de intervenção futuras. As negociações urbanas referem-se

à possibilidade de superação do imenso fosso que comumente se abre entre as ações de preservação do patrimônio cultural e a dinâmica urbana propriamente dita. Uma vez que a lógica que preside as negociações urbanas não é mais a da imposição do parecer técnico imune à deliberação pública e sim a do convencimento da possibilidade de ganhos multilaterais [ ...] ${ }^{21}$
Grandes equipamentos públicos e privados (obrigatoriedade de presença de equipamentos culturais); (6) política de compensações: compensação cultural, isenção de tributação, TDC, penalidades para crimes contra o patrimônio; (7) estudos da paisagem urbana: diretrizes para LUOPS, impacto das grandes obras públicas; (8) código de posturas; (9) tombamentos; (10) bens culturais móveis; (11) medidas urgentes: anteriores a 1940, Criação do Departamento de Cultura na Prefeitura de Belo Horizonte, contratação de serviço técnico especializado, convênios com universidades, ação educativa, criação de lei específica a ser enviada à Câmara Municipal.

19. Carta elaborada por um grupo de conselheiros e encaminhada ao Conselho Deliberativo do Patrimônio Cultural do Município de Belo Horizonte, dentre os quais o autor deste artigo, de onde foi retirada a fonte.

20. Cf. Azevedo; Botelho (2005).

21. Andrade; Esteves (2002, p. 175). 
22. Cf. Andrade e Esteves (2002).

23. Azevedo; Botelho (2005, p. 49).

24. Também enfatizada por Azevedo; Botelho (2005).

25. Cf. Fernandes Júnior; Araújo (2015).
É claro que diante de um instrumento novo como a "negociação urbana" muito deve ser ponderado e refletido.22 Porém, é um importante exemplo para se perceber a capacidade do CDPCMBH de racionalizar e descentralizar a política pública acerca do patrimônio cultural, conseguindo atingir, dessa forma, uma participação ampliada, democrática e plural. ${ }^{23}$

A própria classificação em fases da cronologia de Magni revela algumas descontinuidades importantes do processo, especialmente na questão das representações ${ }^{24}$ na medida em que diferentes governos tentaram alterar a composição do Conselho, com aumento dos representantes do poder público ou indicações diretas dos representantes da sociedade civil, ao invés de acatar as indicações das próprias instituições que o compunham. Do ponto de vista das negociações urbanas, o processo de tombamento também sofreu algumas descontinuidades que, no entanto, não the modificaram o espírito, atingindo apenas sua forma. De início (entre 1986 e 1994) as negociações eram inexistentes e só foram incorporadas como uma política pública a partir de 1994. Inicialmente restritas a alguns casos pontuais, só ganharam forma definitiva a partir de 1997, quando foram estabelecidas as "diretrizes urbanísticas para os conjuntos urbanos tombados" 25 e quando o enquadramento de possibilidades de negociação resultou mais claro. Ainda hoje esta política é prática corrente do Conselho e permite uma participação maior dos empreendedores interessados. Por meio de uma qualificação das suas propostas, que visa seus interesses, mas avaliando se esses interesses podem resultar em um benefício urbanístico e social maior em relação à diretriz original.

\section{A contribuição do campo técnico-científico}

Período da redemocratização do país também foi marcado por uma profunda atuação e avanços científicos nos campos técnicos e acadêmicos. Não há espaço neste artigo para aprofundar esses quesitos, mas cabe citar alguns eventos emblemáticos desses campos realizados em Minas Gerais.

O primeiro deles foi o Arquimemória 2, que ocorreu entre 26 e 30 de agosto de 1987 em Belo Horizonte, promovido pelo IAB-MG e pelo Sphan através da Fundação Nacional Pró-Memória. Em sua apresentação, já apontava suas propostas:

Buscamos dar ao encontro uma forma que refletisse o entendimento dos bens culturais enquanto elementos referenciais de identidade e cidadania - fatores que, em última análise, 
são o fundamento de nossa soberania enquanto nação. Para tanto nos preocupamos em ampliá-lo, trazendo contribuições das diversas áreas de conhecimento que englobam o universo do tema e das visões e conceitos de vários agentes da preservação. ${ }^{26}$
26. Cf. Instituto dos Arquitetos do Brasil - Minas Gerais (1987).

Eram objetivos do encontro: (1) a discussão e a avaliação das políticas e conceitos que têm orientado a ação na área da preservação, da restauração e da revitalização do patrimônio arquitetônico, urbano, ambiental e cultural; (2) promover o intercâmbio de experiências entre os profissionais das diversas áreas e regiões do país, dentro da abrangência do tema; (3) subsidiar a formulação de bases para a atuação na área, de forma a orientar os diversos grupos profissionais, entidades e instituições envolvidas e, em especial, o IAB e seus departamentos. Entre seus participantes estavam nomes como Modesto Carvalhosa, Sonia Rabelo, Fernando Bicudo, Angelo Oswaldo de Araújo Santos, Paulo Mendes da Rocha, Antonio Augusto Arantes, Coelho Neto, Jurema Arnaut, Paulo Ormindo, Benedito Toledo, Carlos Fernando Delphim, Adélia Prado, José Guiherme Magnani, entre outros, e como convidados internacionais destacam se o italiano Giorgio Lombardi e o argentino Miguel Ángel Roca. $\bigcirc$ encontro gerou vários documentos em seus quatro subtemas.

No subtema "Políticas, ação institucional e instrumentos" iá se notava a influência forte da antropologia e o estabelecimento de valores para a nova Constituição, tais como a descentralização política e administrativa, a denúncia dos parcos recursos para a cultura, a necessidade de um planejamento integrado entre os serviços públicos, o reforço à participação da iniciativa privada, a atenção à diversidade e pluralidade da cultura brasileira, a denúncia ao turismo criador de "cenários", a indissociabilidade entre o monumento e o lugar onde se situa, a historicidade como referência também do presente na produção do saber, a necessidade do encontro com a agenda ambiental, a valorização das populações locais e a preocupação com o patrimônio intangível.

No caso do "Patrimônio ambiental urbano", discutiram-se as dicotomias entre urbano e rural, entornos de monumentos e centros antigos, lembranças do passado e o presente da vida das comunidades. Apontou-se a necessidade de preservação das diversas etnias e do patrimônio imaterial, a integração dos centros antigos à malha urbana, o patrimônio como identidade da cidade, incluídos aí não apenas os edifícios, mas também os espaços públicos não edificados. A importância do referencial popular, do desenvolvimento urbano predatório causado pela sobreposição dos valores econômicos à democratização das decisões urbanas, foram temas discutidos, assim como a distância entre a agenda da preservação e a comunidade - materializada na recorrente preservação dos 
27. Cf. Instituto dos Arquitetos do Brasil - Minas Gerais (1992). monumentos das elites e na necessidade de identificação das lutas populares - e, especialmente, a necessidade de se entender os monumentos dentro da cidade.

O subtema "Intervenções, critérios e tecnologias" criticava a ortodoxia dos órgãos centrais de patrimônio contrapondo-o às recentes inovações trazidas pelos órgãos municipais das grandes capitais. $\bigcirc$ novo uso era questão central, mas ele deveria ser muito restrito à forma e às características visuais edilícias dos bens protegidos.

A importância das culturas pré-coloniais e da arqueologia, principalmente para a população leiga, foram parte do subtema "Patrimônio arqueológico e paisagístico".

O segundo evento referencial foi o Arquiamérica 1, realizado em Ouro Preto entre 22 e 25 de setembro de 1992. Também promovido pelo IAB-MG, resultou em alguns documentos de importante fundamentação teórica.

O primeiro deles, denominado Patrimônio da Arquitetura, tratava da ampliação do conceito de patrimônio e discutia questões ligadas à tradição e modernidade, como a descontinuidade do tempo, o progresso linear versus o tempo cíclico, a recuperação dos valores da tradição e suas novas relações com o presente. O documento Memória e ldentidade Nacional versava sobre a importância do suporte edificado como produtor de identidade e referencial simbólico, denunciava o problema da "edição" de um projeto de seleção histórica, a construção controlada de uma identidade nacional e reforçava a necessária pluralidade dessa identidade. Apontando ainda a pertinência desses temas respaldado pela Constituição Cidadã de 1988.

O documento Estruturas Urbanas discorria sobre a natureza contemporânea dos espaços públicos e privados e possíveis critérios referenciais para sua preservação, criticava a cidade considerada em "pedaços" (centros históricos e favelas, por exemplo) e, ao constatar a constante transformação delas, argumentava que:

[...] seria impossível preservar esses momentos através de suas manifestações puramente materiais, como edificações, conjuntos urbanos, obras de arte e relatos. Estas manifestações seriam apenas parte da memória de um processo social relevante para uma determinada comunidade, para uma determinada classe social ou para uma estrutura política, [...] intervir em estruturas urbanas consolidadas pode significar atuar tanto no sentido de manter e/ou incentivar os elementos e dinâmicas que caracterizam essas estruturas, como procurar reverter o sentido do processo, modifica-lo ou mesmo estanca-lo. ${ }^{27}$

O documento apontava ainda a necessidade da gestão democrática das decisões de intervenção em ambientes urbanos e de se entender o caráter dinâmico 
das estruturas urbanas, buscando preservar não só a matéria independentemente das relações sociais.

A Carta de Ouro Preto, que então se produziu, apresentava os seguintes tópicos e recomendações:

- Ampliação do conceito para as diversas territorialidades sociais;

- Sustentabilidade (continuidade entre passado, presente e futuro);

- Democratização do Estado e fortalecimento da sociedade civil;

- Reação contra a pasteurização da industrialização;

- Subtema 1 "Patrimônio da Arquitetura": ampliação do conceito em direção a uma diversidade de análises e de participações; inserção do patrimônio na dinâmica da vida; produção contínua de significados (historicidade do patrimônio);

- Subtema 2 "Intervenções em estruturas urbanas": manutenção da qualidade ambiental em detrimento de monumentos isolados; fortalecimento dos municípios e da participação social; afirmação das diversas identidades; manutenção da pluralidade dos espaços sociais; não gentrificação;

- Subtema 3 "Formação e atuação profissional": reforçava a arquitetura patrimonial no ensino; denunciava a formação acrítica e o silêncio sobre a produção vernacular nos currículos de graduação; e discutia sobre a mudança das relações profissionais do arquiteto com seus "clientes";

- Subtema 4 "Patrimônio natural": discutia sobre os recursos naturais limitados, sem fronteiras e reforçava que a natureza é um conceito cultural, apontando a dicotomia entre as visões biocêntrica e antropocêntrica e a paisagem como possibilidade de fruição;

- Subtema 5 "Memória e Identidade Nacional": apontava a importância do exercício pleno da cidadania (diversidade, solidariedade e alteridade) e de sua não restrição ao edificado, mas também a valores e práticas sociais; dizia da necessidade de articulação com outras políticas setoriais em busca da qualidade de vida e questionava o privilégio aos monumentos em si, inserindo-o nos conjuntos urbanos e rurais.

Como se pode observar através dos documentos derivados destes eventos científicos, os encontros contribuíram fortemente para uma nova visão do que seria o 
28. Cf. Conselho Internacional de Monumentos e Sítios - Brasil (2018).

29. Cf. Carsalade (2014) patrimônio cultural, especialmente na sua interface urbana. Esta visão seria adotada como norte nas ações das décadas seguintes, resultando em 2018, após um longo processo de sedimentação, nas Recomendações de São Paulo para uma nova agenda de preservação patrimonial brasileira (Carta do ICOMOS Brasil sobre a integração patrimônio e sociedade), documento que reforça a questão urbana em seus princípios:

Considerando que o legado patrimonial não se restringe apenas aos grandes monumentos e excepcionalidades, mas passa a constituir um sistema de bens referenciais para a identidade e orientação de povos e comunidades, por isso se constituindo não apenas como documento do passado, mas importante instrumento para lidar com o presente e construir o futuro;

Considerando que a acentuada urbanização mundial tem colocado a questão patrimonial no centro das discussões sobre desenvolvimento sustentável e que este se apresenta além da mera preservação físico/material para sua coexistência com temas convergentes tais como a qualidade de vida, a justiça social, o direito às cidades, a terra urbana, o acesso a bens e serviços, bem como a possibilidade de escolher um estilo de coexistência satisfatório, pleno e agradável, fazendo com que o patrimônio se apresente como fonte de riqueza social em todas as suas dimensões; ${ }^{28}$

Além disto, as reflexões realizadas nestes eventos - por já, de alguma maneira, inserirem a variável sujeito em contraponto ao objeto de preservação -, em sintonia com outros debates nacionais e internacionais, também reforçaram a grande virada epistemológica do campo da restauração retirando a primazia do positivismo e do objeto patrimonial, relativizando-os em relação a grupos sociais e diferentes maneiras de abordar os problemas da preservação. ${ }^{29}$

\section{OS REFLEXOS DA DÉCADA DE 1980 NAS POLÍTICAS PÚBLICAS DAS DÉCADAS SUBSEQUENTES 1990 E 2000}

Concluindo, cabe acrescentar alguns reflexos positivos das ações realizadas em Minas Gerais e no Brasil no período da redemocratização, por exemplo, na forma de políticas públicas e ações específicas da área de patrimônios. 
A política de municipalização do patrimônio cultural em Minas Gerais teve início com a lei estadual 12.040 de 28 de dezembro de 1995 (posteriormente modificada em outras leis até sua forma atuall), que versava sobre a redistribuição do ICMS no estado e colocava o patrimônio cultural como um dos critérios para essa redistribuição. Sua gênese está relacionada à tentativa de promover maior justiça social no repasse desses recursos. O lepha contribuiu para a sua formulação inicial em 1995 e auxiliou no seu aperfeiçoamento até a versão atual incorporando vários elementos da experiência acumulada pela instituição nos anos de vigência da lei.

A lei estadual 12.040 foi depois modificada pela lei 13.803 de 2000 e pela lei 18.030 de 12 de janeiro de 2009, todas elas leis gerais sobre a redistribuição do ICMS no estado que repercutiram na questão do patrimônio cultural. Uma vez que nos critérios relativos à distribuição de $25 \%$ deste imposto aos municípios, o patrimônio cultural faz jus a uma quota parte de 1\%, mediante pontuação atribuída pelo lepha. Embora o Instituto tivesse críticas aos critérios específicos de patrimônio na primeira edição da lei de 1995, preferiu deixá-la como estava na sua revisão de 2000 em função do momento político pelo qual passava o estado, situação que poderia gerar retrocessos na política patrimonial caso se optasse pelas alterações. A edição de 2009, no entanto, já incorpora vários elementos da experiência acumulada pelo lepha, nos 13 anos de sua aplicação. ${ }^{30}$

À época da criação da lei em Minas Gerais, como de resto no Brasil inteiro, eram muito poucos os bens protegidos na instância municipal, mesmo nas grandes capitais. $\bigcirc$ lepha viu nela uma oportunidade de incentivar e induzir o zelo dos municípios pelo ao seu patrimônio local, criando, além do tombamento, dois instrumentos importantes, que foram uma pontuação específica para os tombamentos municipais (além das pontuações "automáticas" dos bens protegidos nos níveis federal e estadual) e outra destinada a políticas de gestão desse patrimônio que foi batizada de Política Cultural Local (PCL). Esses instrumentos foram importantes no sucesso que a lei alcançou na área do patrimônio cultural como indutora de políticas públicas municipais de patrimônio no estado.

Apesar do estranhamento dos municípios que não se reconheciam como cidades históricas, o sucesso da lei como política pública de patrimônio cultural se deu logo no primeiro momento com adesão maciça. As municipalidades, fortemente atraídas pelos recursos que entravam em seus cofres - ainda que o montante financeiro da parcela do ICMS que thes cabia fosse restrito -, vislumbraram a possibilidade de autonomizar seus orçamentos das contribuições federal e estadual, na medida em que 
31. Para maiores informações cf. Biondini; Starling; Carsalade (2014). muitos deles não possuíam estrutura e legislação arrecadatória no nível municipal. $\bigcirc$ sucesso do mecanismo, pelo menos do ponto de vista quantitativo, pode ser medido pela adesão progressiva ao programa, atingindo hoje mais de $80 \%$ dos municípios mineiros e uma cifra de mais de 2.500 bens tombados no seu nível administrativo.

Estes números mostram que a ampliação do conceito de patrimônio cultural em direção ao patrimônio modesto, em reação à monumentalidade e à excepcionalidade, não só caminharam ao encontro da Constituição de 1988, como também resultaram em forte adesão das comunidades à agenda patrimonial. Embora a lei geral, apesar de suas alterações no Legislativo, permanecesse praticamente inalterada no quesito patrimônio, algumas melhorias de procedimentos foram realizadas ao longo do tempo. ${ }^{31}$ Estas melhorias foram possíveis graças a um artigo da própria lei que facultava ao lepha a emissão, a cada ano, de "deliberações normativas" que serviam para corrigir rumos e procedimentos considerados pouco eficientes ou equivocados.

Entre os aspectos positivos do programa, destacam-se a criação de uma política de Estado, diferente de uma ação localizada de governos; a conscientização dos municípios e cidadãos quanto ao seu patrimônio; a geração de investimentos na preservação dos bens culturais do município, fossem eles protegidos por quaisquer dos entes federativos; a aplicação prática da ampliação do conceito de patrimônio antes restrito ao "alto patrimônio", aos bens excepcionais e grandes referências, fazendo com que todas as cidades considerassem sua própria história, sem se sentirem irrelevantes; a inserção na arrecadação estadual e na valorização humana e social de áreas pobres marginalizadas, como o Vale do Jequitinhonha e o Vale do Mucuri; melhorias na capacitação administrativa, gerencial e tecnológica de grande parte dos municípios e a valorização do órgão estadual de patrimônio e, consequentemente, de seu objeto de trabalho e a sua distinção cada vez maior como referência de padrões de qualidade quanto a conceitos, métodos e técnicas.

Podemos apontar entre os aspectos negativos, a preocupação antes arrecadatória que patrimonial em grande parte dos municípios; uma manipulação interesseira e equivocada dos bens municipais; clientelismo e ações conjunturais menores no trato com o patrimônio; oportunismo de empresas de consultoria com objetivos financeiros, e não técnicos, e algumas intervenções equivocadas e descaracterizadoras de bens patrimoniais lem função de pareceres pouco fundamentados, frente à inexistência de corpos técnicos habilitados nos municípios). 
As pressões populares e as novas possibilidades legais obtidas com a Constituição de 1988 criaram em Belo Horizonte o Conselho Deliberativo do Patrimônio Cultural do Município (CDPCM), que empreendeu a proteção de diversos conjuntos urbanos referenciais e simbólicos para a cidade em 1994. A metodologia utilizada para essa proteção não se baseou apenas na materialidade, os edifícios e vias, mas também nas diferentes formas de apropriação da cidade, baseadas em estudos de antropologia urbana, ${ }^{32}$ que buscavam a identificação de unidades espaciais definidas pela prática coletiva de seus usuários. As categorias, "pedaços, manchas, pórticos e trajetos", criadas para compreender estas unidades, foram utilizadas com o objetivo de identificar as particularidades de cada conjunto estudado, a partir dos usos, atividades e grupos sociais que os caracterizam.

Através desta visão, a proteção do patrimônio edificado em Belo Horizonte tem a virtude de não se ater apenas ao construído e ao isolado, ao excepcional e à curiosidade. No seu fundamento, as políticas públicas do município têm como unidade de abordagem a identificação de conjuntos urbanos que apresentam uma coesão de elementos como imagem, apropriação, identidade, história comum, entre outros. Ainda no seu fundamento, essas políticas buscam identificar os elementos intangíveis que propiciam e são propiciados pelo construído, o "argumento" que personaliza cada um deles e que determina seu genius loci.

Essa imagem do ambiente se assenta na força expressiva de seu conjunto, na sua capacidade de se apresentar como criadora de um "lugar" urbano. Para tanto contribuem, além da expressividade geral de seu casario e de suas ruas e da apropriação que nela se dá, as imagens icônicas que o pontuam. Estas imagens icônicas (marcos/ landmarks) são importantes porque a identidade também ocorre a partir de figuras e através da relação significativa com essas figuras que aparecem como "coisas" que pontuam a existência urbana e funcionam como elementos de orientação e identidade.

A ação sistemática do CDPCM, através das Diretrizes para os Conjuntos Urbanos associada a uma política de negociações vem contribuindo para uma qualificação significativa do espaço urbano da cidade. 


\section{PALAVRAS FINAIS}

Como demonstrado no artigo, a partir do caso de Minas Gerais, a luta pela redemocratização do país e seus reflexos na proteção da memória e do patrimônio cultural foi árdua, mas gerou resultados tanto teóricos quanto práticos da mais alta importância. Entretanto, muitas das bandeiras levantadas, apesar do avanços da área, ainda estão por serem realizadas. As conjunturas históricas se sucedem muitas vezes em oposição entre si: há momentos mais propícios para propostas progressistas e outros que dificultam ou quase se contrapõem à sua efetivação. A lição que aprendemos, por todos esses anos, é a de que não há como parar de lutar. Nossos predecessores e nossos pósteros merecem isto. 


\section{REFERÊNCIAS}

FONTES IMPRESSAS

CARSAlADE, Flavio de Lemos. et al. Conselho Deliberativo do Patrimônio Cultural do Município de Belo Horizonte. Carta de Princípios. mimeo, 1990.

INSTITUTO DOS ARQUITETOS DO BRASIL - MINAS GERAIS. ARQUIAMÉRICA, 1. Anais [...]. Belo Horizonte: IAB/MG, 1992.

INSTITUTO DOS ARQUITETOS DO BRASIL - MINAS GERAIS. ARQUIMEMÓRIA, 2. Anais [...]. Belo Horizonte: IAB/MG, 1987.

INSTITUTO DOS ARQUITETOS DO BRASIL - MINAS GERAIS. Encontro pela revitalização da Praça da Estação. Belo Horizonte: IAB/MG, 1981.

LIVROS, ARTIGOS E TESES

AMARAL, Aracy. Marcos Coelho Benjamin. Belo Horizonte: C/Arte, 2000.

ANDRADE, Carlos Drummond. Discurso de primavera e algumas sombras. Rio de Janeiro: José Olympio, 1978.

AZEVEDO, Nilo; BOTELHO, Tarcísio Rodrigues. Gestão participativa e política de patrimônio no município de Belo Horizonte: realidade ou mito? Ciências Sociais Unisinos, São Leopoldo, n. 41, p. $43-52,2005$.

BIONDINI, Isabella Virgínia Freire; STARLING, Mônica Barros de Lima; CARSALADE, Flávio de Lemos. A política do ICMS Patrimônio Cultural em Minas Gerais como instrumento de indução à descentralização de ações de política pública no campo do patrimônio: potencialidades e limites. Cadernos da Escola do Legislativo, Belo Horizonte, v. 16, n. 25, 2014.

CARSALADE, Flávio de Lemos. Instrumentos urbanísticos e preservação do patrimônio. In: FERNANDES JÚNIOR, Edesio; ARAÚJO, Rogério Palhares Zschaber de (orgs.). Entre o urbano, o social e o ambiental: a práxis em perspectiva. Belo Horizonte: Gaia CulturalCultura e Meio Ambiente, 2015. 
CONSELHO INTERNACIONAL DE MONUMENTOS E SÍTIOS - BRASIL. Recomendações de São Paulo para uma nova agenda de preservação patrimonial brasileira (Carta do ICOMOS Brasil sobre a integração patrimônio e sociedade). Boletim ICOMOS Brasil, Belo Horizonte, n. 2, p. 3-12, 2018.

MAGNANI, José Guilherme Cantor. Festa no pedaço: cultura popular e lazer na cidade. São Paulo: Brasiliense, 1984.

MAGNI, Teodoro. O direito ao patrimônio em Belo Horizonte: a institucionalização das práticas e a proteção do Bairro Floresta. Dissertação (Mestrado)-Pontifícia Universidade Católica de Belo Horizonte, 2012.

SANTOS, Regina Bega. Movimentos sociais urbanos. São Paulo: UNESP, 2004.

SOUZA, Marcelo Lopes de; RODRIGUES, Glauco Bruce. Planejamento urbano e ativismos sociais. São Paulo: UNESP, 2004.

SITES

BELO HORIZONTE. Lei Orgânica do Município de Belo Horizonte. Belo Horizonte: Câmara Municipal de Belo Horizonte, 1990. Disponível: <https://bit.ly/3btfpDh>. Acesso em: 3 set. 2020.

INSTITUTO BRASILEIRO DE GEOGRAFIA E ESTATÍSTICA. Pesquisa Nacional por Amostra de Domicílios (PNAD). IBGE, Rio de Janeiro, 2015. Disponível em: <https://bit.ly/3cM6dKW>. Acesso em: $1^{\circ}$ out. 2020.

MINAS GERAIS. Constituição do Estado de Minas Gerais. Belo Horizonte: Assembleia Legislativa de Minas Gerais, 2020. Disponível em: <https://bit.ly/31TLO2I>. Acesso em: 3 set. 2020.

\section{Agradecimento}

Apoio CNPQ Bolsas de Produtividade em Pesquisa - Chamada CNPq Nº9/2018.

Artigo apresentado em 5/12/2019. Aprovado em 29/5/2020.

\section{(cc) BY}

All the contents of this journal, except where otherwise noted, is licensed under a Creative Commons Attribution Licens 